\title{
An investigation on the optimal concentration of oil palm (elaeis guineensis) leaves extract as corrosion inhibitor of carbon steel in deaerated saline solution
}

\begin{abstract}
The effect of Oil Palm (Elaeis guineensis) leaves Extract as a corrosion inhibitor for carbon steel in saline solution has been investigated. The carbon steel was cut and machined to corrosion coupons and immersed into $0.5 \mathrm{M} \mathrm{NaOH}$ solution containing varying inhibitor concentrations $(0.5 \%, 1 \%, 1.5 \%, 2 \%, 2.5 \% \mathrm{v} / \mathrm{v})$ within fifteen weeks. This paper reports the results obtained from; the weight loss method, calculated corrosion rates, variation of surface coverage with temperature, variation of activation energy and heat of adsorption. From the result, it was found that the adsorption of Elaeis guineensis reduced the corrosion rate of the steel in saline solution. The most suitable inhibitor concentration was found to be $2.0 \%$ with inhibition efficiency of $45 \%$. The results obtained shows that the extract could serve as an effective inhibitor for the corrosion of carbon steel in saline solution, with a concentration of $2.0 \%$. The mechanism of inhibition is by chemisorptions and the adsorbed molecules of the inhibitor lies on the surface of the alloy, blocking the active corrosion sites on the alloy. Hence, giving the alloy a higher corrosion resistance in the studied environment.
\end{abstract}

Keywords: elaeis guineensis, carbon steel, saline solution, surface coverage, activation energy
Volume 2 Issue 2 - 2018

\author{
Abhulimen EA \\ Department of Mechanical Engineering, University of Benin, \\ Nigeria
}

Correspondence: Abhulimen EA, Department of Mechanical Engineering, University of Benin, Benin City, Nigeria, Email edeowede@yahoo.com

Received: December 15, 2017 | Published: March 13, 2018

\section{Introduction}

Corrosion simply refers to destructive and unintentional attack on metals. It is extractive metallurgy in reverse. That is, it serves to return metals back to their ores. ${ }^{1}$ Corrosion has been recognized as a phenomenon that has existed for as long as mankind. It has devastated several plants in the industrial age, bringing into focus the need to study and understand it. Since then, mankind has come to accept that corrosion is an inevitable part of the industrial process. The use of inhibitors to protect metals against corrosion is based on the ability of certain individual chemical compounds or mixtures of these, to reduce the rate of corrosion process or to completely suppress this process when they are introduced in small concentrations into a corrosive medium. Steel is used to make a wide range of equipment and metallic structures due to its low cost and good mechanical strength. Much of the steel that is manufactured is exposed to outdoor conditions, often in highly polluted atmosphere where corrosion is considerably more severe than in clean rural environments. ${ }^{2}$

\section{Carbon steel}

Carbon steel refers to steel which has its main interstitial alloying constituent as carbon, in the range of $0.12-2.0 \% .^{3}$ Additionally, steel is considered to be carbon steel when no minimum content is specified or required for chromium, cobalt, molybdenum, nickel, niobium, titanium, tungsten, vanadium or zirconium or any other element to be added to obtain a desired alloying effect; when the specified minimum for copper does not exceed $0.40 \%$ or when the maximum content specified for any of the following elements does not exceed the percentage noted; manganese 1.65 , silicon 0.6 , copper 0.60 (AISI). The term 'carbon steel' may also be used in reference to steel which is not stainless steel. In this use, carbon steel may include alloy steels. As the carbon percentage content rises, steel has the ability to become harder and stronger through heat treatment; however, it becomes less ductile. Regardless of the heat treatment, higher carbon content reduces weldability and lowers the melting point of carbon steels. ${ }^{4}$ Carbon steel has many industrial applications because of its easy availability, low cost, uncomplicated fabrication into water pipe lines as well as cooling water systems. ${ }^{5}$

\section{Oil palm}

Elaeis guineensis is a species of palm, commonly called Africa oil palm or macaw-fat. It is the principal source of palm oil and it is native to West and Southwest Africa, specifically the area between Angola and the Gambia. The species name guineesis, refers to the name for the area, Guinea and not the modern country which now bears that name. Human use of oil palm may date as far back as 5,000years in West Africa. In the late 1800s, archaeologists discovered palm oil in a tomb at Abydos, dating back to 3000 BCE. It was thought that Arab traders brought the oil palm to Egypt. ${ }^{6}$ Oil palm belongs to the Kingdom; Plantae, Family; Aracaceae, Subfamily; Arecoideae, Tribe; Cocoeae, Genus; Elaesis and Species; E Guineesis. ${ }^{7}$ The mature palms are single-stemmed and grow up to $20 \mathrm{~m}$ tall. The leaves are pinnate and reach between $3-5 \mathrm{~m}$ long. A young palm produces about 30 leaves a year. Established palms over 10 year produce about 20 leaves a year. The flowers are produced in dense clusters; each individual flower is small with three sepals and three petals. The palm fruit takes five to six months from pollination to maturity, reddish and grow in bunches. Each fruit is made up of an oily, fleshy outer layer (pericarp) with a single seed (the palm kernel) also rich in oil. When ripe, each bunch of fruit weighs $40-50 \mathrm{~kg}$ (Figure 1). ${ }^{8,9}$ 

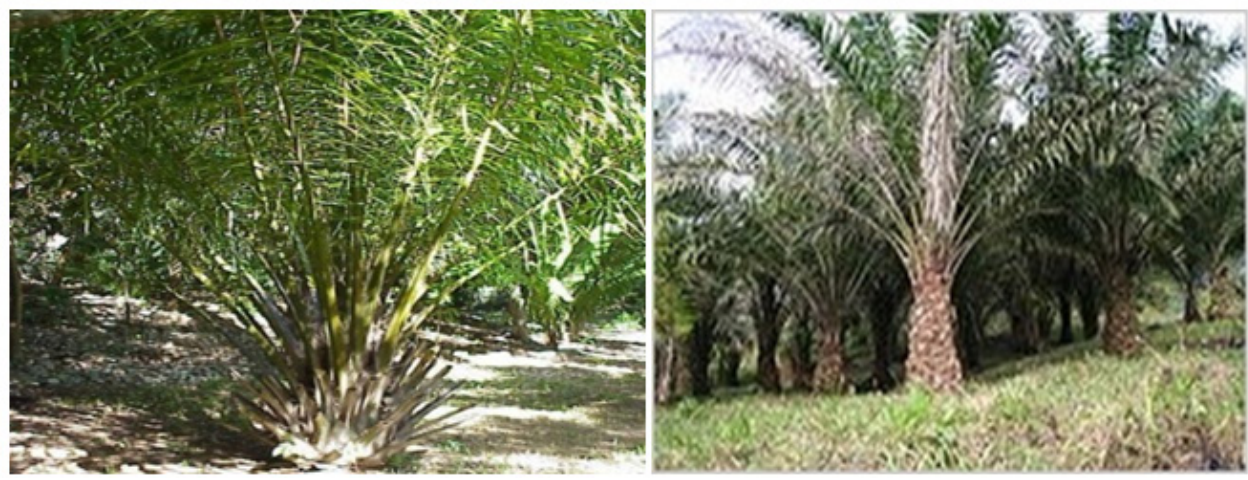

Figure I Oil palm trees with leaves.

\section{Material and methods}

\section{Materials}

The materials used in this work include; folin-ciocalteu reagent,

Table I composition of the experimental steel
Elaeis guineensis leaves extract (the tested inhibitor) obtained from Adola Meche Oil Palm estate in Ohordua, Edo State of Nigeria. The Mild Steel (MS), as- received in form of steel rods was obtained from Ajaokuta Steel Company and composition shown in Table 1.

\begin{tabular}{lllllllll}
\hline$\% \mathrm{C}$ & $\% \mathrm{Si}$ & $\% \mathrm{~S}$ & $\% \mathrm{P}$ & $\% \mathrm{Zn}$ & $\% \mathrm{Ca}$ & $\% \mathrm{~Pb}$ & $\% \mathrm{Al}$ & $\% \mathrm{Co}$ \\
\hline 0.1452 & 0.1374 & 0.04 & 0.05 & 0.0170 & 0.0138 & 0.01732 & 0.0971 & 0.0218 \\
$\% \mathrm{Si}$ & $\% \mathrm{As}$ & $\% \mathrm{~W}$ & $\% \mathrm{Cu}$ & $\% \mathrm{~V}$ & $\% \mathrm{Cr}$ & $\% \mathrm{Ni}$ & $\% \mathrm{Mn}$ & $\% \mathrm{Fe}$ \\
0.0168 & 0.0461 & 0.1344 & 0.01749 & 0.0128 & 0.0284 & 0.01125 & 0.0982 & Balance \\
\hline
\end{tabular}

\section{Equipment}

The equipment used for the work were; water bath, Setra electronic digital weighing balance, model BL-410S, Steel Brush, beaker, Measuring cylinder, desiccators and rotary evaporator.

\section{Methods}

The method involves Preparing samples of the carbon steel as coupons and investigating their corrosion rate by varying the percentage concentration of inhibitors from $0 \%$ through $2.5 \%$ at interval of $0.5 \%$ and varying the temperature to obtain the activation energy, degree of surface coverage, heat of adsorption and free energy values (Figure 2).

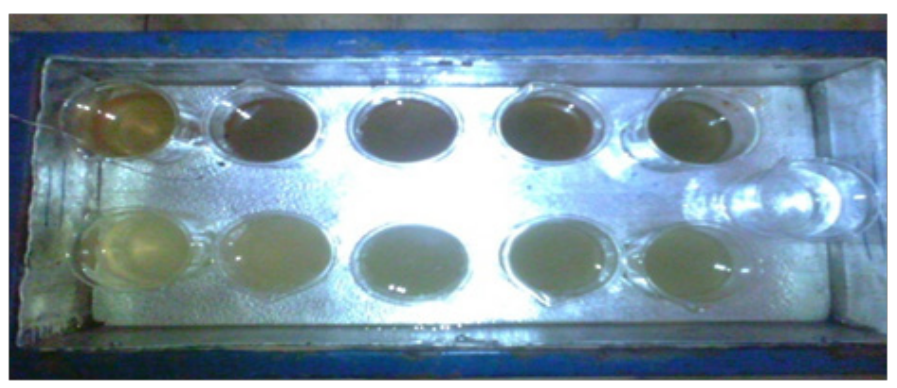

Figure 2 Photograph of Experiment set-up.

Preparation and characterization of the plant extract: The Elaeis guineensis leaves were chopped and freeze-dried for about $48 \mathrm{hrs}$. The dried leaves were ground to powder, and extracted with absolute ethanol at a 1:10 (w/v) solvent ratio under continuous agitation for $24 \mathrm{hrs}$ in the dark. After filtration, the residue was re-extracted twice. The pooled extract was vacuum dried in rotary evaporator, at $40{ }^{\circ} \mathrm{C}$ until the solvent was completely removed to yield a dark green waxy material. The extract was stored in glass vessels, flushed with nitrogen at $-20{ }^{\circ} \mathrm{C}$.

Determination of total phenolic content: The total phenolic content of the extract was determined using folin-cicalteu method. ${ }^{10,11}$ An aliquot of the extract $(0.125 \mathrm{ml})$ was mixed with folin-cicalteu reagent. Then $1.25 \mathrm{ml}$ of saturated $\mathrm{Na}_{2} \mathrm{CO}_{3}$ solution was added and allowed to stand for $90 \mathrm{mins}$ at room temperature. Then, the absorbance was measured at $760 \mathrm{~nm}$. A calibration curve was prepared using standard solution of tannic acid ( 10 to $100 \mu \mathrm{g} / \mathrm{ml}, \mathrm{r}^{2}=0.998$ )

Determination of total flavonoids: Total Flavonoid Content (TFC) of the extract was analyzed according to colometric method. ${ }^{12} 1.5 \mathrm{ml}$ of fruit extract was mixed with $1.5 \mathrm{ml}$ of $\mathrm{AlCl}_{3}(2 \% \mathrm{w} / \mathrm{v})$. It was kept at room temperature for $10 \mathrm{mins}$, and then the absorbance was measured at $358 \mathrm{~nm}$. A calibration curve was prepared using a standard rutin (10 to $\left.100 \mu \mathrm{g} / \mathrm{ml}, \mathrm{r}^{2}=0.964\right)$.

Test for cardiac glycosides: $5 \mathrm{ml}$ of the extract was treated with $2 \mathrm{ml}$ of glacial acetic acid containing one drop of ferric chloride solution. This was underplayed with $1 \mathrm{ml}$ conc. $\mathrm{H}_{2} \mathrm{SO}_{4} \mathrm{~A}$ brown ring at the interface indicates the deoxy sugar characteristics of cardenolics. A violet ring may appear below the ring while in the acetic acid layer; a greenish ring would be visible.

Test for combined anthraquinones: $1 \mathrm{~g}$ of the extract was boiled with $2 \mathrm{ml}$ of $10 \% \mathrm{HCl}$ for $5 \mathrm{~min}$. The mixture was filtered while hot and allowed to cool. The cooled filtrate was partitioned against equal volume of chloroform and the chloroform layer was transferred into a clean dry test-tube using a clean pipette. Equal volume of $10 \%$ ammonia solution was added into the chloroform layer, shaken and allowed to separate. The separated aqueous layer was observed for any colour change; delicate rose pink colour indicates the presence of an antraquinone. 
Test for reducing compounds: $10 \mathrm{ml}$ of distilled water was added to about $1 \mathrm{~g}$ of the sample in a test-tube and boiled for $5 \mathrm{~min}$. The mixture was filtered while hot and the cooled filtrate made alkaline with $20 \%$ sodium hydroxide solution. The resulting solution was boiled with an equal volume of Benedit qualitative solution in a water bath. The presence of a brick red precipitate would depict the presence of a reducing compound.

Test for tannins: $1 \mathrm{~g}$ of the extract was boiled with $20 \mathrm{ml}$ of distilled water for $5 \mathrm{~min}$ in a water bath and was filtered while hot. $1 \mathrm{ml}$ of cooled filtrate was distilled to $5 \mathrm{ml}$ with distilled water and a few drops (2-3) of $10 \%$ ferric chloride were observed for any formation of precipitates and any colour change. A bluish black precipitate indicated the presence of tannin.

Test for saponins: $0.5 \mathrm{~g}$ of the extract was boiled with $5 \mathrm{ml}$ of distilled water (in a bath for about 10min). The mixture was filtered while hot and allowed to cool. $2.5 \mathrm{ml}$ of the filtrate was diluted to $10 \mathrm{ml}$ with distilled water and shaken vigorously for $2 \mathrm{~min}$. frothing indicated the presence of saponins.

Test for flavonoids: $1 \mathrm{~g}$ of the extract was boiled with $10 \mathrm{ml}$ of distilled water for about $5 \mathrm{~min}$ and filtered while hot. Few drops of $20 \mathrm{~g}$ sodium hydroxide solution were added to $1 \mathrm{ml}$ of the cooled filtrate. A change to yellow colour which on addition of acid changed to colourless depicted the presence of flavonoids.

Test for alkaloids: $1 \mathrm{~g}$ of the extract was boiled with water and $10 \mathrm{ml}$ of $\mathrm{HCl}$ on a water bath and filtered. The $\mathrm{pH}$ of the filtrate was adjusted with ammonia to about 6-7. A very small quantity of picric acid and Mayer's reagent (potassium mercury iodide solution) was added separately to about $0.5 \mathrm{ml}$ of the filtrate in different test tubes and observed. A coloured precipitate or turbidity indicated the presence of alkaloids.

\section{Results and discussion}

\section{Elaeis Guineensis Phytochemical Composition}

The phytochemical constituents of oil palm leaves extract are shown in Table 2. The results obtained indicate that saponnin, tannin, alkaloids, flavonoid and Phenolic groups are present in the ethanol extract of Elaeis guineensis. The inhibition efficiency of the extract could therefore be attributed to the presence of these phytochemical components.

Table 2 phytochemical analysis of Elaeis guineensis leaves extract

\begin{tabular}{ll}
\hline Constituent & Status \\
\hline Anthraquinone glycoside & - \\
Flavonoids & + \\
Phenolic group & + \\
Saponins & + \\
Carbohydrates & - \\
Steroids & - \\
Tannins & + \\
Alkaloids & +
\end{tabular}

\section{Visual inspection}

Visual inspection is a Non Destructive Evaluation method for corrosion monitoring. It is the simplest and the oldest inspection technique. ${ }^{13}$ Although this technique has some limitations, it is however the first approach in corrosion inspection. The visual observation of coupons (without and with inhibitor) after $5 \mathrm{hr}$ of exposure reveals changes in color of the coupons from bright shiny surfaces to dull ones. Pits were observed on the samples as indications of corrosion attack by the acidic media. However, the changes in color as well as the presence of pits were more intense with the solutions without inhibitor. It decreased with increasing concentration of inhibitor up to $2.0 \%$ and then changes insignificantly.

\section{Weight loss measurement after immersion duration}

The weight loss data is presented as a chart in Figure 3. It can be seen that the weight loss for the sample without inhibitor was highest at each point in time. The weight loss however decreased with addition of inhibitor. It can be seen also that as the inhibitor concentration gets to $2.0 \%$ the weight loss was only $0.14 \mathrm{~g}$ at $225 \mathrm{mins}$. Additional concentration gave no significant difference in weight loss. This perhaps is because, at that concentration, adequate inhibitive film barrier for corrosion protection was achieved.

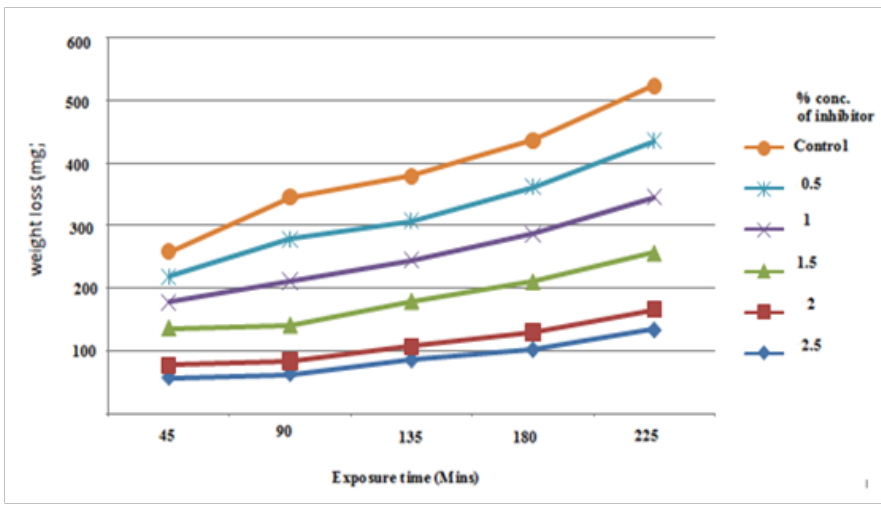

Figure 3 Weight loss as a function of immersion duration for varying concentrations inhibitor.

\section{Corrosion rate}

The result from corrosion rate test is displayed in Figure 4. It is evident that the corrosion rate decreased at each point in time with increasing concentration of inhibitor up till 2.0\%. Beyond 2.0\%, there was no significant difference in the corrosion rate. This could be attributed to the fact that adequate inhibitive film barrier for corrosion protection was achieved at $2.0 \%$ concentration of inhibitor and further addition of inhibitor would not be necessary.

\section{Inhibition efficiency}

Figure 5 shows the inhibition efficiency of the various inhibitor concentrations used for the weight loss test. From the chart, it can be inferred that the highest inhibition efficiency of $45 \%$ was achieved at $2.0 \%$ concentration of inhibitor. This shows that the oxide films formed on the carbon steel surface at that concentration were thick and stable enough to diminish corrosion rate due to the passivation influence of the inhibitor. Further increase in inhibitor concentration gave no notable increase in efficiency. 


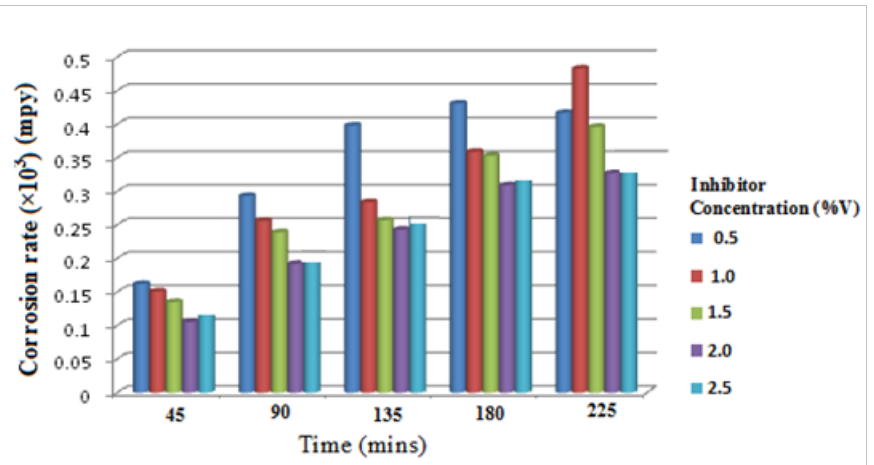

Figure 4 Variation of corrosion rate with exposure time for varying concentrations of inhibitor.

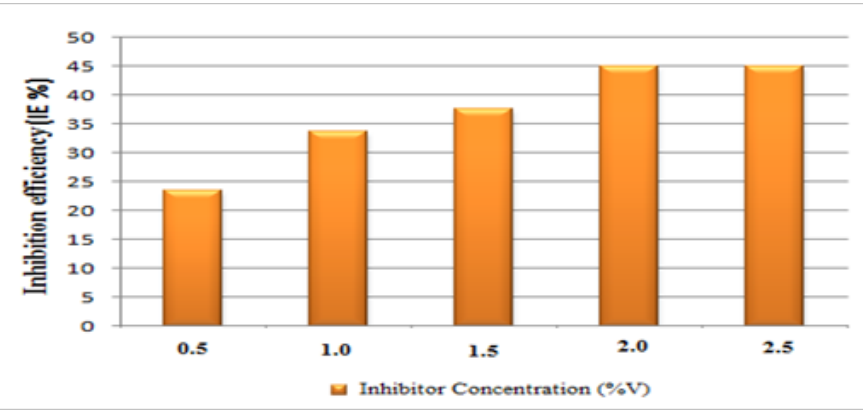

Figure 5 Inhibition efficiency versus inhibitor concentration.

\section{Surface coverage}

The surface coverage $(\theta)$ values for different concentrations of the inhibitors in both media have been evaluated from the weight loss data. At any instant, a fraction of the metal surface is covered by the inhibitor molecules and the uncovered fraction reacts with acid as it does in the absence of the inhibitor. The nature of the inhibitor interaction with the corroding surface has been deduced from the adsorption characteristics of the inhibitor. The experimental result in Figure 6 showed that at $2.0 \%$, adequate adsorption had occurred and the adsorbed molecules of the inhibitor sufficiently lies on the surface of the alloy, blocking the active corrosion sites on the alloy. Hence further increase of the inhibitor concentration yielded no significant difference.

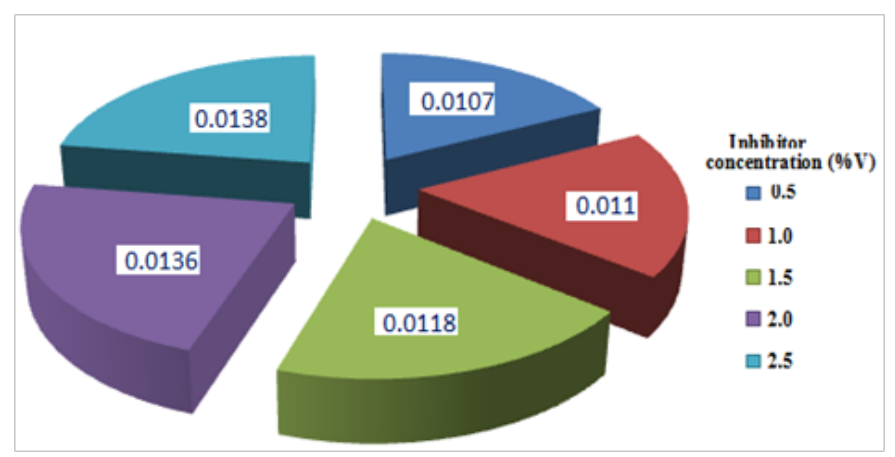

Figure 6 Degree of surface coverage for varying concentration of inhibitor.

\section{Activation energy}

Activation energy (E) for mild steel in deaerated saline solution in the presence and in the absence of the inhibitor was calculated and result displayed in Figure 7 below. The activation energy at different concentration of the inhibitor is plotted. Values for inhibited systems reduce with increase in inhibitor concentration, indicating that the inhibitor exhibit high inhibition tendency. However, this trend discontinued at $2.0 \%$, with the activation energy remaining at $-7.562 \mathrm{~kJ} / \mathrm{mol}$, owing to the fact that the optimum concentration has been reached.

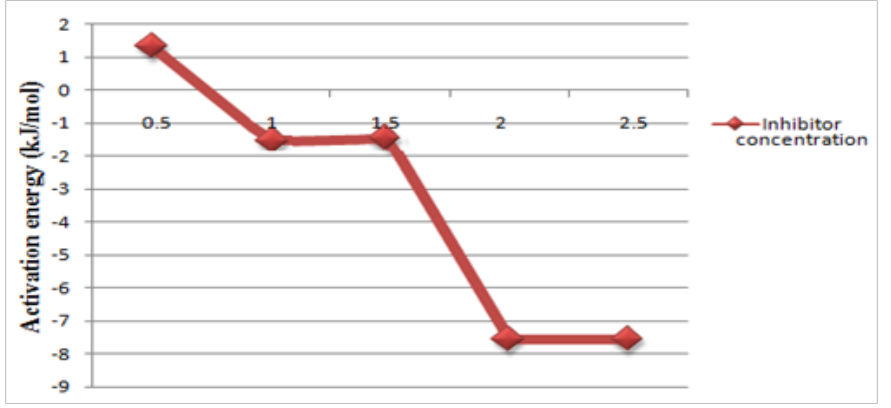

Figure 7 Variation of activation energy with inhibitor concentration.

\section{Heat of adsorption}

Figure 8 below shows the result for heat of adsorption. The values increase up to $1.703 \mathrm{~kJ} / \mathrm{mol}$. This is an indication that the adsorption of inhibitor molecules is chemisorptions. It is a chemical reaction between the carbon steel surface and the inhibitor, generating new bonds at the adsorbent surface thereby shielding it from further corrosion. The values however did not increase at concentrations above $2.0 \%$, suggesting that the optimum concentration may have been reached.

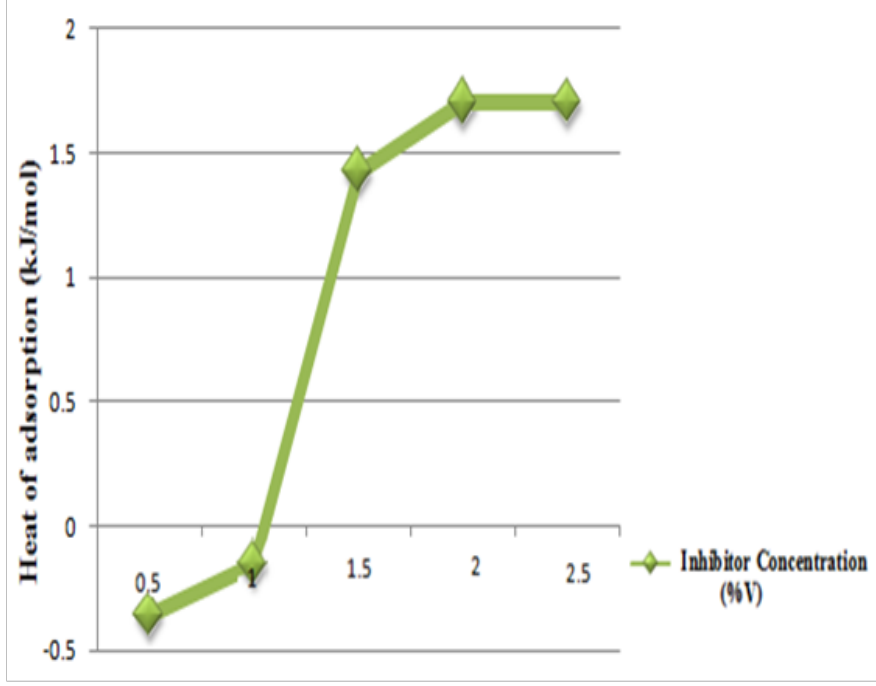

Figure $\mathbf{8}$ Variation of heat of adsorption with inhibitor concentration.

\section{The free energy $(\Delta \mathbf{G})$}

The result for free energy $(\Delta \mathrm{G})$ at various concentration of inhibitor is shown in Figure 9 below. The values increase from $-0.521 \mathrm{~kJ} / \mathrm{mol}$ at $0.5 \%$ inhibitor concentration, up to $3.690 \mathrm{~kJ} / \mathrm{mol}$, at $2.0 \%$ inhibitor concentration. The positive values suggest strong impediment in the spontaneity of the corrosion reaction and the high values indicate that the corrosion reaction on the carbon steel surface is reduced by the inhibitor. The increased trend of free energy $(\Delta \mathrm{G})$ values however 
discontinued from $2.0 \%$ inhibitor concentration. This suggests that the optimum concentration of inhibitor may have been achieved.

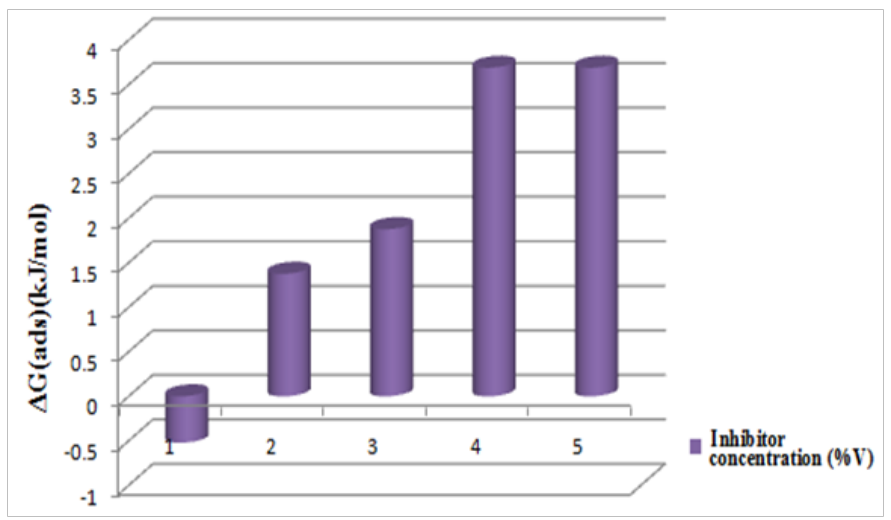

Figure 9 Variation of free energy $(\Delta G)$ with inhibitor concentration.

\section{Conclusion}

The results and discussion above show that:

a) Elaeis guineensis leaf extract can effectively be used as a corrosion inhibitor of carbon steel in deaerated saline solution.

b) At $2.0 \%$ concentration of Elaeis guineensis leaf extract, optimum corrosion inhibition is achieved.

c) The inhibition efficiency (IE), surface coverage, heat of adsorption as well as free energy $(\Delta \mathrm{G})$ were found to have increased with increased concentration of inhibitor up to $2.0 \%$ concentration and then gave no significant increase with further increase in inhibitor concentration

d) Weight loss, corrosion rate and activation energy decreased with increasing concentration of inhibitor till $2.0 \%$ concentration and further increase in inhibitor concentration gave no significant change. The decrease in the values of activation energy indicates that the addition of the plant extract limits metal dissolution of carbon steel.

\section{Acknowledgment}

None.

\section{Conflict of interests}

The authors declare that there is no conflict of interests regarding the publication of this paper.

\section{References}

1. Davies A. Hand book on condition monitoring. London: Chapman and Hall; 1998:102-112.

2. Morcillo M, Fuente D, Díaz J Simancas, et al. Long-term atmospheric corrosion of mild steel. Corrosion Science. 2011;53(2):604-617.

3. http://www.steelplatesforsale.com/blog/what-is-carbon-steel.html

4. Knowles, Peter Reginald. Design of structural steelwork. 2nd ed. UK: Taylor \& Francis; 1987.

5. Melchers RE, Jeffery R. Corrosion Reviews. 2005;184.

6. Corley RHV, Lee CH. The physiological basis for genetic improvement of oil palm in Malaysia. Euphytica. 1992;60(3):179-184.

7. https://www.usgbc.org/resources/usda-grin-taxonomy-plants-database

8. Kiple, Kenneth F, Conee Ornelas, et al. The Cambridge World History of Food. Cambridge University Press; 2000.

9. Obahiagbon FI. A Review: Aspects of the African Oil Palm (Elaeis guineesis). American Journal of Biochemistry and Molecular Biology. 2012;1-14.

10. Almey AAA, Khan CAJ, Zahri IS, et al. Total phenolic content and primary antioxidant activity of methanolic and ethanolic extract of aromatic plant leaves. Int food Res J. 2010;7:1079-1084.

11. Wolfe $\mathrm{K}, \mathrm{Wu} \mathrm{X}$, Liu RH, et al. Antioxidant activity of apple peels. J Agric Food Chem. 2003;51(3):609-614.

12. Luximon-Ramma A, Bahorun T, Soobrattee AM, et al. Antioxidant activities of phenolic, proanthocyanidin and flavonoid components in extracts of Acacia fistula. J Agr Food Chem. 2002;50(18):5042-5047.

13. Fontana M, Greene ND. Corrosion Engineering. 3rd ed. McGraw-Hill: Singapore; 1987. 